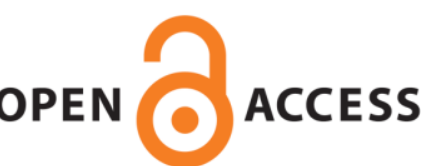

OPEN ACCESS

UWS Academic Portal

\title{
Left ventricular function during exercise in trained pre-adolescent soccer players
}

Unnithan, Viswanath; Roland, Thomas W.; George, Keith; Lord, Rachel; Oxborough, David

Published in:

Scandinavian Journal of Medicine \& Science in Sports

DOI:

$10.1111 / \mathrm{sms} .13258$

Published: 30/11/2018

Document Version

Peer reviewed version

Link to publication on the UWS Academic Portal

Citation for published version (APA):

Unnithan, V., Roland, T. W., George, K., Lord, R., \& Oxborough, D. (2018). Left ventricular function during exercise in trained pre-adolescent soccer players. Scandinavian Journal of Medicine \& Science in Sports, 28(11), 2330-2338. https://doi.org/10.1111/sms.13258

\section{General rights}

Copyright and moral rights for the publications made accessible in the UWS Academic Portal are retained by the authors and/or other copyright owners and it is a condition of accessing publications that users recognise and abide by the legal requirements associated with these rights.

Take down policy

If you believe that this document breaches copyright please contact pure@uws.ac.uk providing details, and we will remove access to the work immediately and investigate your claim. 
PROFESSOR VISWANATH UNNITHAN (Orcid ID : 0000-0001-5147-1679)

DR DAVID OXBOROUGH (Orcid ID : 0000-0002-1334-3286)

Article type : Original Article

LEFT VENTRICULAR FUNCTION DURING EXERCISE IN TRAINED PRE-ADOLESCENT SOCCER PLAYERS

Viswanath. B. Unnithan ${ }^{1}$, Thomas.W. Rowland ${ }^{1}$, Keith George ${ }^{2}$, Rachel Lord ${ }^{3}$ and David.

Oxborough $^{2}$

${ }^{1}$ Institute of Clinical Exercise and Health Science, School of Health Sciences, University of the West of Scotland, Hamilton, Scotland, ${ }^{2}$ Research Institute for Sport and Exercise Sciences, Liverpool John Moores University, Liverpool, UK, ${ }^{3}$ Cardiff Centre for Exercise and Health, Cardiff Metropolitan University, Cardiff, UK.

Address for correspondence:

Professor V.B. Unnithan, Ph.D., FACSM

Institute of Clinical Exercise and Health Science

School of Science and Sport

University of the West of Scotland

Hamilton

Scotland, UK

Tel: 01698894413

E-mail: vish.unnithan@uws.ac.uk

Running Head: Cardiovascular responses in youth soccer

This article has been accepted for publication and undergone full peer review but has not been through the copyediting, typesetting, pagination and proofreading process, which may lead to differences between this version and the Version of Record. Please cite this article as doi: $10.1111 / \mathrm{sms} .13258$

This article is protected by copyright. All rights reserved. 


\section{Abstract}

It is unclear, what the underlying cardiovascular mechanisms are that give rise to the high level of aerobic fitness seen in youth soccer players. The aim of the study was to evaluate global and regional markers of systolic and diastolic function in a group of pre-adolescent soccer players during an incremental exercise test. Twenty-two, male soccer players (SP) from two professional soccer clubs (age: $12.0 \pm 0.3$ years) volunteered for the study. Fifteen recreationally active boys (CON), of similar age (age: $11.7 \pm 0.2$ years) were also recruited. All boys underwent a cycle ergometer test to exhaustion. Cardiac dimensions were determined using M-mode echocardiography. During submaximal and maximal exercise, continuous-wave Doppler ultrasound techniques were used to derive stroke volume (SVIndex). Tissue-Doppler imaging was used to quantify systolic (S'adj) and diastolic function ( $\mathrm{E} ; \mathrm{E}^{\prime}$ adj and $\mathrm{E} / \mathrm{E}^{\prime}$ ) at rest and both submaximal and maximal exercise intensities. Speckle tracking echocardiography was used to determine peak longitudinal $\varepsilon$ at submaximal exercise intensities. SP demonstrated significantly $(P \leq 0.05)$ greater peak $\mathrm{VO}_{2}$ values than CON (SP: $48.0 \pm 5.0$ vs CON: $\left.40.1 \pm 7.5 \mathrm{~mL} \cdot \mathrm{kg}^{-1} \cdot \mathrm{min}^{-1}\right)$. Allometrically scaled to body surface area left ventricular end-diastolic volume (LVEDV) was larger $(P \leq 0.05)$ in the SP $(51.3 \pm 9.0)$ compared to CON $(44.6 \pm 5.8$ $\left.\mathrm{mL} \cdot \mathrm{BSA}^{1.5}\right)$. At the same relative, submaximal exercise intensities, the SP demonstrated greater SVIndex, cardiac output (QIndex) and E. No differences were noted for peak longitudinal $\varepsilon$ during submaximal exercise. Factors that augment pre-load and LV volume appear to determine the superior aerobic fitness seen in the soccer players.

Key Words: Youth Soccer; Tissue-Doppler Imaging; Cardiac Strain; Exercise

\section{Introduction}

Adolescent and youth soccer within professional clubs is characterised by training and match-play intensities that are in excess of $70 \%$ of the maximal aerobic capacity of the young player ${ }^{1}$. Furthermore, the tactical and technical training that these athletes undergo can generate physiological loads in excess of $85 \%$ of the maximal heart rate ${ }^{1}$. This type of training load produces acute cardiovascular adjustments in stroke volume, cardiac output and total peripheral resistance that results in a transient volume overload ${ }^{2}$ on the left ventricle (LV). Evidence exists to suggest that 
the physiological superiority of adolescent and youth soccer players compared to their recreationally active peers is a response to long-term training rather than any growth or maturity-linked effects ${ }^{3}$. Further, the impact of training status on LV structure and function at rest may help explain their superior physical performance capacity ${ }^{4,5}$. Whilst the evaluation of cardiac structure and function at rest can provide some mechanistic insight with regard to exercise performance ${ }^{6}$, the interrogation of LV functional responses during exercise has greater potential to explain individual differences in physiological performance capacity ${ }^{4,7}$. Previous work in this area has focussed upon identifying the determinants of superior aerobic capacity in both male and female, highly trained, adolescent soccer players $^{4,7}$. It is unclear, however, the impact that a reduced number of years of soccer training exposure would have on influencing cardiac morphology and function at both rest and uniquely during exercise in the pre-adolescent player.

The emergence of speckle tracking echocardiography (STE), which reliably assesses regional myocardial tissue deformation in the longitudinal plane of motion ${ }^{8}$ has the potential to provide further mechanistic insight into the link between LV performance and maximal aerobic capacity. There are a small number of studies that have characterised cardiac deformation during exercise in the child and adolescent populations ${ }^{8,9}$. To date, this approach has not been adopted in highly trained pre-adolescent soccer players in an attempt to differentiate the impact of training status on regional LV function.

Consequently, the aims of this study were; 1 ) to evaluate LV morphology and global and regional markers of systolic and diastolic function at rest in highly-trained, pre-adolescent soccer players (SP) and healthy control participants (CON), 2) to compare global and regional LV systolic and diastolic responses at two, similar relative exercise intensities in the SP and CON and 3) to compare maximal exercise performance capacity (maximal aerobic capacity), as well as global markers of LV systolic and diastolic function at peak exercise intensity .It was hypothesised that the SP would demonstrate: 1) larger LV morphology and superior global LV function than the CON at rest; 2) no significant difference in global and regional markers of LV function compared to the CON during submaximal exercise and 3) greater QIndex and SVIndex at peak exercise compared to the CON.

\section{Methods}

\section{Participants}

Twenty-two highly trained youth soccer players (SP, mean age: $12.0 \pm 0.3$ years) and 15 recreationally active individuals (CON, mean age: $11.7 \pm 0.2$ years) volunteered to participate in the study. The SP were recruited from two, Category One Youth Soccer Academies affiliated to two professional English Championship soccer clubs. The SP training profiles were as follows: $4.5 \pm 1.5$ years training, $11 \pm 1$ months per year training, $4 \pm 1$ training sessions per week and $9.4 \pm 2.4$ hours per week of training. The SP also played one competitive match per week and had been engaged in competitive soccer matches for $4 \pm 2$ years. The CON were all recreationally active. Recreational activity was defined as taking part in physical education classes at school and the occasional out of school sports

This article is protected by copyright. All rights reserved. 
activity. These participants, however, were not involved in any systematic training. All participants underwent a physical examination and completed a medical history questionnaire. Exclusion criteria included the use of any medications that would influence cardiovascular function and any personal or early family history of cardiovascular disease. Informed parental and participants' written informed consent was obtained prior to participation. All procedures performed in the study were in accordance with the ethical standards of the Declaration of Helsinki and the study was approved by Staffordshire University Research Ethics Committee.

\section{Study Design}

The study employed a prospective, cross-sectional, cohort assessment of cardiac and exercise performance in highly trained pre-adolescent SP and CON. Within testing sessions, repeated measures of a number of physiological variables were completed at rest and during progressive exercise. All testing took place at the training grounds of the two soccer clubs and at a local school for the CON participants. Participants were instructed to refrain from exercise on the day preceding the test. Furthermore, all participants were also informed to refrain from consuming any drinks containing sugar or caffeine as well as the consumption of any food in the two hours preceding the testing session.

\section{Protocol/Measurements}

Physical activity and training questionnaires ${ }^{4}$ were completed prior to the testing. Following this, stature, sitting height and body mass were measured. Maturity status was quantified using both selfassessment, Tanner Stage method ${ }^{10}$ and maturity offset ${ }^{11}$. Resting arterial blood pressure was recorded in the left arm by an automated blood pressure cuff (Boso, Medicus, Jungingen, Germany) and heart rate was assessed by a 12-lead electrocardiogram (ECG) (CardioExpress SL6, Spacelabs Healthcare, Washington US). Resting echocardiographic measurements were taken in the supine position. This was then followed by resting echocardiographic measurements taken in an upright position on the cycle ergometer. Participants then completed a cycle ergometer test to volitional exhaustion, with echocardiographic and open circuit, breath-by-breath metabolic measurements obtained throughout. The participants pedalled at $60 \mathrm{rpm}$ with an initial workload of $20 \mathrm{~W}$ and this increment was maintained until $60 \mathrm{~W}$ Each stage was 3 minutes in duration.

Echocardiographic measurements were taken $90 \mathrm{~s}$ into each stage for the first three stages. After this third stage, the workload increments were adjusted on an individual basis until volitional exhaustion. Final echocardiographic measurements were taken immediately prior to peak exercise. Submaximal exercise inter-group comparisons were made at two relative exercise intensities (RE), to ensure that cardiovascular evaluations were made at the same approximate metabolic load. These intensities were at $40 \mathrm{~W}$ in the $\mathrm{SP}$, which equated to $46.7 \pm 5.6 \% \mathrm{VO}_{2}$ peak and $20 \mathrm{~W}$ in the CON, which equated to $46.5 \pm 8.0 \% \mathrm{VO}_{2}$ peak. These two intensities were denoted as $\mathrm{RE}(1)$. The second relative exercise intensity comparison was at $60 \mathrm{~W}$ in the $\mathrm{SP}$, this equated to $56.8 \pm 6.0 \% \mathrm{VO}_{2}$ peak and $40 \mathrm{~W}$ in the CON: $60.5 \pm 10.4 \% \mathrm{VO}_{2}$ peak and denoted as RE (2).

This article is protected by copyright. All rights reserved. 


\section{Echocardiographic Measurements: Resting indices of $L V$ structure}

All echocardiographic procedures prior to and during the cycle ergometer test were performed by the same experienced sonographer (DO) using a commercially available ultrasound system (VividQ Ultrasound System, GE Ltd, Horton, Norway). Measurements of resting LV dimensions (LV end diastolic dimension [LVED], LV end systolic dimension [LVES]), diastolic wall thicknesses (interventricular septum [VSd] and posterior wall [PWd]) were made in accordance with American Society of Echocardiography (ASE) guidelines ${ }^{12}$ using M-mode echocardiography. These parameters were scaled to the square root of body surface area ${ }^{13}$. Relative wall thickness (RWT) was calculated according to ASE guidelines in order to provide a marker of LV geometry. LV end-diastolic volume (LVEDV) and LV end-systolic volume (LVESV) were determined using the Simpson's biplane method from apical 4- and 2-chamber views ${ }^{12}$. LVEDV and LVESV were then allometrically scaled ${ }^{13}$ to BSA ${ }^{1.5}$.

\section{Echocardiographic Measurements: Indices of $L V$ function at rest and during incremental exercise}

Following supine resting measurements, participants sat in an upright position on an electronically braked cycle ergometer (Lode, Corival, Groningen, Netherlands). Imaging of the left ventricle was performed at rest and at 1:30 s into each of the first three stages, from the focused, apical fourchamber view and the suprasternal notch with the participant in an upright, but forward-leaning position on the cycle ergometer. Offline analysis included, peak early diastolic filling velocity (E). Where clearly discernible, the E wave was measured. During faster heart rates, however, fusion of the $E$ and atrial $(A)$ waves meant that a single peak diastolic filling velocity was measured, but still termed $\mathrm{E}$ for ease of comparison. Pulsed wave tissue-Doppler imaging determined peak longitudinal mitral, lateral, annular velocities in systole $\left(S^{\prime}\right)$ and early diastole $\left(E^{\prime}\right)$. Both $E^{\prime}$ and $S^{\prime}$ were adjusted for heart size by LV Length ${ }^{14}$. Similar to conventional blood flow assessment, the peak diastolic myocardial velocity was utilized, when fusion of $E$ and $A^{\prime}$ occurred. $E / E^{\prime}$ (E ratio) was calculated as an estimate of LV filling pressure and thus preload ${ }^{15}$.

Stroke volume (SV) was calculated using continuous-wave Doppler from the suprasternal notch to detect ascending aortic flow. The velocity-time integral (VTI) at rest and at peak exercise was calculated and multiplied by the resting, upright, LV outflow tract cross-sectional area. Subsequently, rest and peak exercise cardiac output (Q) was determined by multiplying SV by the heart rate (HR) (as determined from the R-R interval from the same cardiac cycle on the ECG inherent to the echocardiographic machine). Acceptable reliability of the Doppler echocardiographic technique for estimating SV has previously been established by Rowland and Willers ${ }^{16}$. Both Q and SV were adjusted for body surface area ( $Q$ Index and SVIndex). Arterial venous oxygen difference $\left(\mathrm{AVO}_{2}\right)$ was computed as $\mathrm{VO}_{2} / \mathrm{Q}$.

This article is protected by copyright. All rights reserved. 
A focused apical 4-chamber orientation of the LV was acquired and optimized to improve endocardial delineation using frequency and gain with a single focal zone placed mid LV cavity to reduce the impact of beam divergence. Frame rates were maintained as high as possible within the working range of 40 to $90 \mathrm{fps}$. Subsequent offline analysis using dedicated speckle tracking software (Echopac V6.0, GE Healthcare, Horton, Norway) provided assessment of longitudinal strain $(\varepsilon)$, systolic strain rate (SSR) and early diastolic strain rate (DSR) (as defined as the peak value in diastole allowing for early and late diastolic fusion). Global values were calculated as an average of six myocardial segments from the basal, mid and apical septum and lateral walls. Strain data was only analysed at the two relative exercise intensities [(RE (1) and RE (2)] due to poor feasibility of speckle tracking at higher heart rates. All images were digitally stored and analysed off-line. The average of three to five consecutive cardiac cycles was calculated and recorded. Good reliability of the inexercise longitudinal $\varepsilon$ data has also been established by this research team ${ }^{8}$.

\section{Gas exchange measurements during exercise}

Gas exchange data was obtained using an online gas analysis system (Cortex MetaMax 3B, Cortex Biophysik $\mathrm{GmbH}$, Leipzig, Germany). The online gas analyser was calibrated prior to each visit according to the manufacturer's instructions, using a known gas concentration and a $3 \mathrm{~L}$ syringe for manual volume calibration of the flow turbines. Peak $\mathrm{VO}_{2}$ was defined as the highest $15 \mathrm{~s}$ mean value during the final stage of exercise. This value was expressed relative to body mass. The criteria used to determine a true maximal effort were: 1) Participants demonstrated subjective evidence of exhaustion (hyperpnea, sweating and fatigue), 2) a maximal RER value greater than 1.0 or 3) a heart rate in excess of $180 \mathrm{bpm}^{4}$. HR was assessed by ECG and a Polar Heart rate monitor (Polar Electro, Kempele, Finland).

\section{Statistical Methods}

A one-way ANOVA was used for the inter-group comparisons of: 1) cardiac morphology data, 2) resting global and tissue-Doppler derived variables, 3) global and tissue-Doppler derived measures at the two relative exercise intensities and 4) maximal exercise intensity global and tissue-Doppler derived variables. A sample size of 22 SP provided a (1- $\beta$ ) of $80 \%$ at an alpha level of 0.05 . All statistical analyses were performed using SPSS version 23 (NY, USA).

\section{Results}

There were small, but statistically significant inter-group differences in chronological age and stature, but all other physical or maturity status data were similar between groups (Table 1). The SP demonstrated a significantly higher peak $\mathrm{VO}_{2}$ (SP: $48.0 \pm 5.0$ vs $\mathrm{CON}: 40.1 \pm 7.5 \mathrm{~mL} \cdot \mathrm{kg}^{-1} \cdot \mathrm{min}^{-1} ; P \leq 0.05$ ).

This article is protected by copyright. All rights reserved. 
All participants satisfied the criteria for an exhaustive effort on the cycle ergometer and there was no between group difference for maximal HR (SP: $189 \pm 7$ vs. CON: $186 \pm 9$ beats. $\min ^{-1}$ ).

\section{Resting LV structure and function}

The SP had significantly $(P \leq 0.05)$ larger scaled LVES·BSA ${ }^{-0.5}, \mathrm{VSd} \cdot \mathrm{BSA}^{-0.5}, \mathrm{LVEDV} \cdot \mathrm{BSA} \mathrm{A}^{-1.5}$ than the CON (Table 2). Resting heart rate was significantly lower and resting SV index was significantly greater $(P \leq$ 0.05 ) in SP than controls (Table 3). There was no significant between group differences in $\mathrm{AVO}_{2}$ difference or QIndex at rest, but QIndex reserve (SP: $71 \pm 4.0$ vs CON: $66 \pm 8 \%$ ) was significantly greater $(P \leq 0.05)$ in the SP. Peak aortic blood flow velocity was significantly $(P \leq 0.05)$ higher at rest in the SP compared to the CON. There was no inter-group difference in LVEF and $S^{\prime}$ at rest and no significant inter-group difference in $\mathrm{S}^{\prime}$ reserve (SP: $60 \pm 7$ vs $\mathrm{CON}: 60 \pm 11 \%$ ). Peak E was significantly ( $P$ $\leq 0.05$ ) higher in the SP compared to the CON at rest, but all other indices of resting diastolic function were not different between groups (Table 3 ) including E'adj reserve (SP: $41 \pm 12$ vs CON: $45 \pm 16 \%)$.

\section{LV function during submaximal and maximal exercise}

At RE (1), SVIndex, QIndex and E were all significantly greater $(P \leq 0.05)$ in the SP compared to the CON (Table 4 and see Figures 1-3). Significantly, greater QIndex and E values were also noted for the SP compared to the CON at RE (2), Table 4 and Figures 1-3. There were no inter-group differences for $S$ 'adj at RE (1) and RE (2). The only inter-group differences that emerged at maximal exercise were for peak aortic velocity and $S^{\prime}$ and in each case, SP presented with significantly ( $\left.P \leq 0.05\right)$ greater values than CON (Table 3).

\section{Longitudinal $\varepsilon$ during submaximal exercise}

No inter-group differences were identified for peak longitudinal $\varepsilon$ at the two relative exercise intensities, RE (1): SP: $-20.2 \pm 3.2$ vs CON: $-20.5 \pm 2.5 \%$ and RE (2): SP: $-19.3 \pm 2.9$ vs CON: $-19.9 \pm 2.1 \%$. Similarly, no significant inter-group differences were identified for SSR at the two relative exercise intensities. RE (1), SP: $-1.4 \pm 0.1$ vs CON: $-1.3 \pm 0.21 / \mathrm{s}$ and RE (2): SP: $-1.6 \pm 0.3$ vs CON: $-1.6 \pm 0.21 / \mathrm{s}$. There was also no significant difference in DSR between the two groups; RE (1), SP: $2.2 \pm 0.5$ vs CON: $2.1 \pm 0.41 / \mathrm{s}$ and RE (2): SP: $2.3 \pm 0.3$ vs CON: $2.0 \pm 0.31 / \mathrm{s}$.

This article is protected by copyright. All rights reserved. 


\section{Discussion}

The major findings of this study were that there was evidence of larger LV morphology and greater peak aortic velocities and $\mathrm{E}$ at rest in the SP compared to the CON. Superior SVIndex, QIndex and E in the SP during submaximal exercise were identified. Based on the cardiac strain data (peak longitudinal $\varepsilon$, SSR and DSR) there was no evidence to suggest that training status resulted in superior intrinsic contractility in the SP during submaximal exercise. There was, however, evidence of superior global systolic function ( $\mathrm{S}^{\prime}$ and peak aortic velocity) at maximal exercise in the SP.

There was some evidence to suggest that exercise-induced LV remodelling had occurred in the elite pre-adolescent SP based on linear dimensions and volume data. These morphologic changes suggest that highly trained SP can present some characteristics of the "Athlete's Heart", even at a preadolescent stage. This supports previous research in pre-adolescent soccer players ${ }^{17,18}$ and older male $^{4}$ and female ${ }^{7}$ adolescent soccer players, who had been exposed to slightly longer, systematic soccer training (7-9 years of training). In a cross-sectional study, it is only possible to speculate, that the greater LVEDV seen in the SP is a by-product of training-induced increases in plasma volume ${ }^{19}$ and/or repetitive haemodynamic overload resulting in eccentric chamber hypertrophy ${ }^{20}$. The similarity in morphological findings in the present study to that seen in the older, adolescent soccer players ${ }^{4,7}$ suggests either a genetic pre-disposition for a larger LV or exercise-induced, LV cardiac remodelling in response to limited training exposure in the pre-adolescent soccer players. These findings are further supported by the conclusions from McLean et al's ${ }^{21}$ systematic and metaanalysis of the electrical and structural adaptations of the paediatric athlete's heart. In this comprehensive review, these authors concluded that clear evidence existed of exercise-induced cardiac re-modelling in the pre-adolescent years.

At rest, SP generated a greater SVIndex compared to CON, which is a likely consequence of an increased LVEDV in the presence of unaltered $\mathrm{LVEF}^{22}$. Left atrial evaluation was beyond the scope of the present study, but evidence exists to suggest that exercise-induced atrial re-modelling exists in pre-adolescent athletes and this could influence SVIndex ${ }^{23}$. As, these authors established a moderate relationship between increases in left atrial volume and increases in SVIndex at rest following a 5 month training period. Peak aortic velocity (a marker of systolic function) at rest was augmented in the SP and was also a product of the greater LVEDV seen in the young players. The only significant between group differences for global markers of diastolic function at rest was a higher $E$ in the SP; that existed even after adjusting for differences in resting HR. A higher $E$ in the SP, independent of $H R$, likely contributes to the increased LVEDV via a possible plasma-volume induced increase in preload $^{19}$.

It is unlikely that this finding represents substantive evidence of superior diastolic function in the SP at rest, as there was a lack of inter-group differences in $\mathrm{E}^{\prime}$. The findings from the literature are equivocal, as enhanced ${ }^{24,25}$ and unchanged ${ }^{22} E$ values have been noted in highly trained, child endurance athletes at rest.

This article is protected by copyright. All rights reserved. 
At the two similar, submaximal relative exercise intensities, the SP demonstrated superior E, SVIndex and QIndex compared to the CON. This evidence suggests that when exercising at the same metabolic load, factors that augment pre-load (enhanced plasma volume and greater LVEDV) drive superior mitral in-flow, with concomitant increases in SVIndex and QIndex. Greater SVIndex was also identified in both adolescent male and female soccer players compared to recreationally active control subjects when exercising at absolute, submaximal workloads ${ }^{4,7}$. These authors speculated that increased ventricular volume acted as the pre-cursor for the elevated SVIndex seen in their study rather than any training-derived functional adaptation in diastolic function. LVEDV was not measured in either of these studies. The present study indirectly confirms this hypothesis, as greater LVEDV values were noted in the pre-adolescent SP compared to the CON participants.

The superior QIndex reserve in the present study in the SP can potentially be explained by a longitudinal $\varepsilon$ reserve. In the present study, LV mechanics were not investigated at maximal exercise. Nottin et al. ${ }^{26}$ have hypothesized that a lack of difference in LV mechanics at rest between trained and untrained individuals represented a mechanical reserve on which athletes' can draw on at maximal exercise to enhance cardiac performance. This strain reserve reflects the LV capacity to enhance contractile function during exercise, irrespective of resting values (QIndex reserve), as seen in the SP in the present study. The importance of contractile reserve evaluation by exercise echocardiography has been highlighted in mitral regurgitation patients ${ }^{27}$. Furthermore, QIndex reserve has been used in the past to explain the capacity of the LV to recover following heart failure ${ }^{28}$. These findings have been supported by further Dobutamine stress echocardiography research ${ }^{29}$ that has demonstrated a direct relationship between contractile reserve and improvements in LVEF following $\beta$-blocker therapy in patients with advanced chronic heart failure. The improved LVEF underpins the improved contractile reserve and provides the basis for the ability for $\mathrm{CHF}$ patients to respond to stress, as seen during exercise.

A paucity of research exists with regard to the quantification of diastolic function during upright exercise in children. Consequently, a novel aspect of the present investigation was the interrogation of global markers of diastolic function in an upright body position. This approach mimics the posture for most sports activities and minimizes the confounding effects of altered body position on haemodynamic responses during exercise ${ }^{30}$.

At the two relative exercise intensities, SP presented with greater E compared to CON. These findings mimic $E$ data obtained in adolescent male and female soccer players ( 15 years) exercising at absolute workloads during upright cycle ergometer exercise ${ }^{4,7}$.These authors demonstrated superior $E$ in the SP during submaximal exercise, but this did not achieve statistical significance. There were no inter-group differences in $\mathrm{E}^{\prime}$, when exercising at the two relative exercise intensities in the present study. These findings are similar to that seen in the adolescent male and female soccer players when exercising at absolute submaximal workloads ${ }^{4,7}$.

This article is protected by copyright. All rights reserved. 
At the two relative exercise intensities, there were no inter-group differences in $E / E^{\prime}$ ( $E$ ratio). $E$ ratio is considered an indirect marker of left atrial pressure and these findings suggest that the increase in $E$ in both SP and CON at the submaximal intensities was a product of enhanced LV relaxation properties, rather than the result of any elevated atrial pressures. A similar pattern was also noted in older adolescent male and female soccer players ${ }^{4,7}$. Data from the present study suggests that there is no strong evidence to support the hypothesis that enhanced diastolic function during exercise in these highly trained pre-adolescent soccer players is responsible for their superior aerobic capacity. Based on the S' data, there was also no evidence of superior systolic function in the SP during submaximal exercise. These findings are similar to previous work from our research group in older, highly trained, adolescent male and female soccer players ${ }^{4,7}$.

In the present study, there was no evidence that training status altered peak longitudinal $\varepsilon$ at rest, which confirms data from elite, adult male cyclists ${ }^{26}$. At the two, relative, submaximal exercise intensities, there were no inter-group differences in peak longitudinal $\varepsilon$ and these findings support the global systolic measurements $\left(S^{\prime}\right)$. There is a paucity of research with respect to the quantification of regional wall deformation during exercise in pre-adolescent populations. Recent work by Pieles et $\mathrm{al}^{9}$ demonstrated a pattern of increased peak longitudinal $\varepsilon$ from rest with a subsequent plateau during submaximal, supine cycle ergometry in recreationally active boys and girls (13.2 years). Furthermore, adult data during supine and semi-supine exercise also demonstrates a similar a pattern for peak longitudinal $\varepsilon^{31,32}$. The lack of inter-group differences in the present study in peak longitudinal $\varepsilon$, suggested no intrinsic differences in contractility during submaximal exercise.

Two markers of global systolic function ( $\mathrm{S}^{\prime}$ adj and peak aortic velocity) demonstrated significant inter-group differences at maximal exercise intensity. This may stem from the larger LVEDV seen in the SP inducing earlier and better stretching of myocardial fibres from a more efficient use of the Frank-Starling mechanism ${ }^{20}$. The researchers acknowledge that this finding is not supported by the submaximal peak longitudinal $\varepsilon$ findings and could represent a limitation of the tissue-Doppler approach to quantifying systolic function. The systolic findings at maximal exercise were somewhat similar to the pattern seen in highly trained, adolescent male soccer players ${ }^{4}$. This previous investigation demonstrated augmented peak aortic velocity values at maximal exercise in the adolescent male soccer players compared to their recreationally active peers, but they did not achieve statistical significance (SP: $231 \mathrm{vs.} \mathrm{CON:} 208 \mathrm{~cm} \cdot \mathrm{s}^{-1}$ ). There were no significant inter-group differences for any markers of diastolic function at maximal exercise intensity and this mimicked the findings previously seen in both the male and female adolescent soccer players ${ }^{4,7}$.

This article is protected by copyright. All rights reserved. 
There were some limitations associated with the study. A cross-sectional design limits our ability to delineate the specific influence of training on our outcome measures and the use of speckle tracking echocardiography limits the frame rate that can be used. Consequently, strain and strain rate can only be determined at submaximal exercise intensities during upright cycle ergometry exercise. In addition, due to ethical constraints, plasma volume data was unable to be obtained from the participants. An extensive evaluation of bi-atrial and right ventricular function ${ }^{33}$ was beyond the scope of the present study. It is possible, however, that an interrogation of these two areas would provide a more comprehensive understanding of the role of elite youth soccer training on morphological and functional adaptations in the pre-adolescent player.

In conclusion, there was some evidence in the present study of exercise-induced LV remodelling in the highly trained youth soccer players. The SP also presented with increased early diastolic filling and greater peak aortic velocity at rest compared to the CON; this contradicted our original hypothesis. Based on the tissue-Doppler and strain data, there was no real evidence to suggest that training status had any impact on submaximal diastolic and systolic function. Superior systolic function and greater cardiac reserve were noted at maximal exercise intensity in the highly trained pre-adolescent soccer players compared to their recreationally active peers. The similarity in the morphological attributes of the pre-adolescent SP at rest and their functional characteristics during submaximal and maximal exercise to that seen in the previous study with adolescent male soccer players ${ }^{4}$; suggests that the combined influence of genetic pre-disposition and responsiveness to training influences cardiac morphology and functional adaptations in these young players. It is acknowledged that the true effect of high-intensity, intermittent soccer training on cardiac morphological and functional adaptations in highly trained young soccer players can only be answered through the longitudinal evaluation of these young athletes and this question warrants further investigation.

\section{Perspective}

The vast amount of published literature in this area has quantified cardiac morphology and function at rest in the highly trained, young, endurance athlete ${ }^{21}$ and demonstrated exercise-induced morphological and functional changes in these individuals. There is a paucity of knowledge of the impact that high-intensity, intermittent exercise (characteristics of soccer training and match-play) can have on changes in cardiac structure and function at rest and uniquely during exercise. This is particularly true in the pre-adolescent athlete that has not yet been exposed to the changes in the hormonal milieu during puberty, but is exposed to high volume and intensity training. While the primary focus of this study was not a screening study, it was also encouraging to see that the adaptations noted in the soccer players were not commensurate with any pathological structure and function in these young athletes.

This article is protected by copyright. All rights reserved. 


\section{Acknowledgements}

The authors would like to thank Mr. Marc Campbell (Wolverhampton Wanderers FC) and Dr. Russ Wrigley (Blackburn Rovers FC) with their help in the organization of the data collection sessions at the football clubs and Ms. Katie Davis and Ms. Leanne Brittle for their help with the organization of the testing sessions of the recreationally active control participants at the school (Staffordshire University Academy). We gratefully acknowledge the help of: Ms. Jenna Hulme, Mr Mark Bailey and Mr. Justin Rich from Staffordshire University for their technical support with the data collection at the school and the two football clubs and finally we appreciate the dedication and enthusiasm shown by the boys at the school and the two football clubs for their participation in the research project.

This research did not receive any specific grant from funding agencies in the public, commercial, or not-for-profit sectors. No companies or manufacturers will benefit from the results of the present study and the authors report no conflict of interests.

\section{References}

1.Wrigley RD, Drust B, Stratton G, Scott M, Gregson W. Quantification of the typical weekly in-season training load in elite junior soccer players .J Sports Sci 2012; 30(15):1573- 1580.

2. Mitchell JH, Haskell W, Snell P, Van Camp SP. Task Force 8: Classification of Sports. J Am Coll Cardiol 2005; 45(8):1364-7.

3. Wrigley RD, Drust B, Stratton G, Atkinson G, Gregson W. Long-term Soccer-specific training enhances the rate of physical development of academy soccer players independent of maturation status. Int J Sports Med 2014; 35(13):1-5.

4. Rowland TW, Garrard M, Marwood S, Guerra ME, Roche D, Unnithan VB. Myocardial performance during progressive exercise in athletic adolescent males. Med Sci Sports Exerc 2009; 41(9):17211728.

5. Pelliccia A, Caselli S, Sharma S, et al. European Association of Preventive Cardiology (EAPC) and European Association of Cardiovascular Imaging (EACVI) joint position statement: recommendations for the indication and interpretation of cardiovascular imaging in the evaluation of the athlete's heart. European Heart Journal doi: 10.1093/eurheartj/ehx532. [Epub ahead of print]

This article is protected by copyright. All rights reserved. 
6. Rowland TW, Unnithan VB, MacFarlane NG, Gibson NG, Paton JY. Clinical manifestation of the

"athlete's heart" in prepubertal male runners. Int J Sports Med 1994; 15(8): 515-519.

7. Rowland T, Unnithan V, Roche D, Garrard M, Holloway K, Marwood S. Myocardial function and aerobic fitness in adolescent females. Eur J Appl Physiol 2011;111(9):1991-1997.

8. Unnithan VB, Rowland T, Lindley MR, Roche DM, Garrard M, Barker P. Cardiac strain during upright cycle ergometry in adolescent males. Echocardiography 2015; 32(4): 638-643.

9. Pieles GE, Gowing L, Forsey J, et al. The relationship between biventricular myocardial performance and metabolic parameters during incremental exercise and recovery in healthy adolescents. Am J Physiol Heart Circ Physiol 2015; 309(12):H2067-2076.

10. Tanner J. Growth at adolescence ( $2^{\text {nd }}$ ed.). Oxford: Blackwell Scientific, 1962. p. 31-39.

11. Sherar LB, Mirwald RL, Baxter-Jones AD, Thomis M. Prediction of adult height using maturitybased cumulative height velocity curves. J Pediatr. 2005; 147(4):508-14.

12. Lang RM, Badano LP, Mor-Avi V, et al. Recommendations for cardiac chamber quantification by echocardiography in adults: an update from the American Society of Echocardiography and the European Association of Cardiovascular Imaging. J Am Soc

Echocardiogr 2015; 28(1):1-39.

13. Batterham, AM, George, KP, Whyte G, Sharma S, McKenna W. Scaling cardiac structural data by body dimensions: a review of theory, practice, and problems. Int J Sports Med 1999;20(8):495-502.

14. Batterham A, Shave R, Oxborough D, Whyte G, George K. Longitudinal plane colour tissueDoppler myocardial velocities and their association with left ventricular length, volume, and mass in humans. Eur J Echocardiogr 2008; 9(4):542-6.

15. Nagueh SF, Smiseth OA, Appleton CP, et al. Recommendations for the evaluation of left

This article is protected by copyright. All rights reserved. 
ventricular diastolic function by echocardiography: An update from the American Society of Echocardiography and the European Association of Cardiovascular Imaging. J Am Soc Echocardiogr 2016; 29(4): 227-314.

16. Rowland TW, Willers ME. Reproducibility of Doppler measures of ventricular function during maximal upright cycling. Cardiol Young. 2010; 20: 676-679.

17. Zdravkovic M, Perunicic J, Krotin M, et al. Echocardiographic study of early left ventricular remodeling in highly trained preadolescent footballers. J Sci Med Sport

2010; 13(6): 602-606.

18. Pela G, Crocamo A, Li Calzi M, et al. Sex-related differences in left ventricular structure in early adolescent non-professional athletes. Eur J Prev Cardiol 2016; 23(7): 777-784.

19. Koch $\mathrm{G}$, Rocker L. Plasma volume and intravascular protein masses in trained boys and fit young men. J Appl Physiol 1977; 43(6):1085-1088.

20.Obert P, Nottin S, Baquet G, Thevenet D, Gamelin F-X, Berthoin, S. Two months of endurance training does not alter diastolic function evaluated by TDI in 9-11-year-old boys and girls. Br J Sports Med 2009; 43(2): 132-135.

21. McLean G, Riding N R, Arden C L et al. Electrical and structural adaptations of the paediatric athlete's heart: A systematic review and meta-analysis. Br J Sports Med 2018; 52: 230.

22. Nottin S, Nguyen LD, Terbah M, Obert P. Left ventricular function in endurance-trained children by tissue-doppler imaging. Med Sci Sports Exerc 2004; 36(9): 1507-1513.

23. D’Ascenzi FD, Solari M, Anselmi F, et al. Atrial chamber remodelling in healthy pre-adolescent

This article is protected by copyright. All rights reserved. 
athletes engaged in endurance sports: A study with a longitudinal design. The CHILD study. Int J

Cardiol 2016; 223: 325-330.

24. Obert P, Mandigouts S, Nottin S, Vinet A, N'Guyen LD, Lecoq AM.

Cardiovascular responses to endurance training in children: effect of gender. Eur J Clin Invest 2003; 33(3):199-208.

25. Triposkiadis F, Ghiokas S, Skoularigis I, Kotsakis A, Giannakoulis I, Thanopoulos V. Cardiac adaptation to intensive training in prepubertal swimmers Eur J Clin Invest 2002;32(1):16-23.

26. Nottin S, Doucende G, Schuster-Beck I, Dauzet M, Obert P. Alteration in left ventricular normal and shear strains evaluated by 2D-strain echocardiography in the athlete's heart. J Physiol. 2008; 586 (19):4721-4733.

27. Lee R, Haluska B, Leung DY, Case C, Mundy J, Marwick TH. Functional and prognostic implications of left ventricular contractile reserve in patients with asymptomatic severe mitral regurgitation.

Heart 2005; 91: 1407-1412.

28. Naqvi TZ, Goel RK, Forrester JS, Siegel RJ. Myocardial contractile reserve on dobutamine echocardiography predicts late spontaneous improvement in cardiac function in patients with recent onset idiopathic dilated cardiomyopathy. J Am Coll Cardiol 1999; 34 (5):1537-44.

29. Eichhorn EJ, Grayburn PA, Mayer SA, et al. Myocardial contractile reserve by Dobutamine stress echocardiography predicts improvement in ejection fraction with $\beta$-blockade in patients with heart failure: The $\beta$-blocker evaluation of survival trial (BEST). Circulation 2003; 108: 2336-2341.

30. Rowland $T$, Unnithan V, Barker $P$, Guerra $M$, Roche $D$, Lindley $M$. Orthostatic effects on echocardiographic measures of ventricular function. Echocardiography 2012; 29 (5):523-527.

This article is protected by copyright. All rights reserved. 
31. Doucende G, Schuster I, Rupp T, et al. Kinetics of left ventricular strains and torsion during incremental exercise in healthy subjects. The key role of torsional mechanics for systolic-diastolic coupling. Circ Cardiovasc Imaging 2010; 3(5): 586-594.

32. Stohr EJ, McDonnell B, Thompson J, et al. Left ventricular mechanics in humans with high aerobic fitness: adaption independent of structural remodeling, arterial haemodynamics and heart rate. $J$ Physiol 2012; 590(9): 2107-2119.

33. D’ Ascenzi FD, Pelliccia A, Valentini F et al. Training-induced right ventricular remodelling in preadolescent endurance athletes: The athlete's heart in children. Int J Cardiol 2017; 236: 270-275.

\section{Figure Captions}

Fig 1: QIndex responses of soccer players $(n=22)$ and controls $(n=15)$ at the two comparable, relative exercise intensities (RE (1) and RE (2)). The symbols denote the mean values. Horizontal error bars denote the variability (SD) in relative exercise intensity $\left(\% \mathrm{VO}_{2} \mathrm{max}\right)$ and vertical error bars denote the variability (SD) in QIndex. At both RE (1) and RE (2), the SP demonstrated significantly greater QIndex responses than the CON.* denotes $p \leq 0.05$.

Fig 2: SVIndex responses of soccer players $(n=22)$ and controls $(n=15)$ at the two comparable, relative exercise intensities (RE (1) and RE (2)). The symbols denote the mean values. Horizontal error bars denote the variability (SD) in relative exercise intensity $\left(\% \mathrm{VO}_{2} \mathrm{max}\right)$ and vertical error bars denote the variability (SD) in SVIndex. At RE (1), the SP demonstrated significantly greater SVIndex responses than the CON. There was no significant inter-group difference in SVIndex at RE (2). * denotes $p \leq 0.05$.

Fig 3: $E$ responses of soccer players $(n=22)$ and controls $(n=15)$ at the two comparable, relative exercise intensities (RE (1) and RE (2)). The symbols denote the mean values. Horizontal error bars denote the variability (SD) in relative exercise intensity $\left(\% \mathrm{VO}_{2} \max \right)$ and vertical error bars denote the variability (SD) in E values. At both RE (1) and RE (2), the SP demonstrated significantly greater $E$ responses than the CON. * denotes $\mathrm{p} \leq 0.05$.

This article is protected by copyright. All rights reserved. 
Table 1: Physical characteristics of soccer players (SP; $n=22$ ) and control participants (CON; $n=15$ ). Values are mean \pm standard deviation.

\begin{tabular}{|c|c|c|}
\hline & $S P(n=22)$ & $\operatorname{CON}(n=15)$ \\
\hline Age (years) & $12.0 \pm 0.3^{*}$ & $11.7 \pm 0.2$ \\
\hline Stature $(\mathrm{m})$ & $1.51 \pm 0.06 *$ & $1.47 \pm 0.06$ \\
\hline Body Mass (kg) & $40.2 \pm 5.9$ & $43.3 \pm 12.1$ \\
\hline BSA $\left(m^{2}\right)$ & $1.29 \pm 0.12$ & $1.32 \pm 0.18$ \\
\hline Tanner (AU) & $2 \pm 1$ & $3 \pm 1$ \\
\hline Maturity Offset (years) & $-3.8 \pm 0.5$ & $-3.9 \pm 0.6$ \\
\hline Age at PHV (years) & $15.8 \pm 0.7$ & $15.7 \pm 0.6$ \\
\hline
\end{tabular}

* $P \leq 0.05$. Body surface area (BSA); peak height velocity (PHV)

This article is protected by copyright. All rights reserved. 
Table 2. Left ventricular measurements at rest in soccer players (SP; $n=22$ ) and control participants (CON; $n=15)$. Values are mean \pm standard deviation.

\begin{tabular}{|c|c|c|}
\hline & $S P(n=22)$ & $\operatorname{CON}(n=15)$ \\
\hline LVED $(\mathrm{mm} \cdot \mathrm{BSA}$ & $39.4 \pm 2.6$ & $39.0 \pm 2.5$ \\
\hline $\operatorname{LVES}\left(\mathrm{mm} \cdot \mathrm{BSA}^{-0.5}\right)$ & $26.7 \pm 1.8^{*}$ & $25.2 \pm 2.5$ \\
\hline $\operatorname{VSd}\left(\mathrm{mm} \cdot \mathrm{BSA}^{-0.5}\right)$ & $6.8 \pm 0.6^{*}$ & $6.2 \pm 0.5$ \\
\hline $\mathrm{PWd}\left(\mathrm{mm} \cdot \mathrm{BSA}^{-0.5}\right)$ & $6.3 \pm 0.8$ & $5.8 \pm 0.7$ \\
\hline RWT (cm) & $0.32 \pm 0.05$ & $0.30 \pm 0.04$ \\
\hline LVEDV $\left(\mathrm{mL} \cdot \mathrm{BSA}^{-1.5}\right)$ & $51.3 \pm 9.0 *$ & $44.6 \pm 5.8$ \\
\hline LVESV $\left(\mathrm{mL} \cdot \mathrm{BSA}^{-1.5}\right)$ & $17.6 \pm 3.5$ & $16.1 \pm 2.7$ \\
\hline LVEF (\%) & $65.7 \pm 4.1$ & $63.6 \pm 4.7$ \\
\hline
\end{tabular}

$* P \leq 0.05$. Left ventricular (LV) end diastolic dimension (LVED), LV end systolic dimension (LVES), interventricular septum (VSd) and posterior wall (PWd), Relative wall thickness (RWT), LV enddiastolic volume (LVEDV) and LV end-systolic volume (LVESV) and LV ejection fraction (LVEF).

This article is protected by copyright. All rights reserved. 
Table 3. Cardiovascular measures at rest and maximal exercise in trained soccer players (SP) and control participants (CON). Values are mean \pm standard deviation.

\begin{tabular}{lll}
\hline & SP $(n=22)$ & CON $(n=15)$ \\
\hline Heart Rate (bpm) & & \\
Rest & $66 \pm 9^{*}$ & $75 \pm 12$ \\
Maximum & $189 \pm 7.0$ & $186 \pm 9.0$
\end{tabular}

SVIndex $\left(\mathrm{mL} \cdot \mathrm{m}^{-2}\right)$

Rest

$47 \pm 9 * \quad 42 \pm 4$

Maximum

$56+9$

$52 \pm 7$

QIndex $\left(L \cdot \mathrm{min}^{-1} \cdot \mathrm{m}^{-2}\right)$

$3.06 \pm 0.59 \quad 3.17 \pm 0.54$

Rest

Maximum

$10.5 \pm 1.50$

$9.67 \pm 1.42$

$\mathrm{AVO}_{2}$ difference $\left(\mathrm{mL} \cdot 100 \mathrm{~mL}^{-1}\right)$
$8.0 \pm 2.3$
$6.8+1.9$

Rest

Maximum

$14.3+1.3$

$12.8+2.3$

SYSTOLIC FUNCTION

Peak aortic velocity $\left(\mathrm{cm} \cdot \mathrm{s}^{-1}\right)$

Rest

$138.5 \pm 19.7 * \quad 118.7 \pm 22.3$

Maximum

$250.0 \pm 25.1 * \quad 215.7 \pm 33.1$

$\mathrm{S}^{\prime} \operatorname{adj}\left(\mathrm{cm} \cdot \mathrm{s}^{-1} \cdot \mathrm{mm}^{-1}\right)$

This article is protected by copyright. All rights reserved. 
Maximum

\section{DIASTOLIC FUNCTION}

$E\left(\mathrm{~cm} \cdot \mathrm{s}^{-1}\right)$

$90 \pm 15.0 *$

$82 \pm 7$

Rest

Maximum

$177 \pm 16$

$172 \pm 13$

$E^{\prime} \operatorname{adj}\left(\mathrm{cm} \cdot \mathrm{s}^{-1} \cdot \mathrm{mm}^{-1}\right)$

Rest

$1.92 \pm 0.38$

$1.70 \pm 0.48$

Maximum

$3.31 \pm 0.43$

$3.14+0.38$

$E / E^{\prime}$

Rest

$6.3 \pm 1.5$

$7.1 \pm 2.1$

Maximum

$7.0+1.2$

$7.5 \pm 0.9$

* $P \leq 0.05$. Stroke volume adjusted for body surface area (SVIndex) and cardiac output also adjusted for body surface area (QIndex). Arterial venous oxygen difference $\left(\mathrm{AVO}_{2}\right)$. Peak early diastolic filling velocity (E). Peak longitudinal mitral annular velocities in systole $\left(S^{\prime}\right)$ and early diastole ( $\left.E^{\prime}\right)$. Both $E^{\prime}$ and $S^{\prime}$ were adjusted (adj) for heart size by LV length. E/E' was calculated as an estimate of LV filling pressure and thus preload.

This article is protected by copyright. All rights reserved. 
Table 4. Cardiovascular measures at two relative exercise intensities in trained soccer players (SP) and control participants (CON). Values are mean \pm standard deviation.

\begin{tabular}{lll}
\hline & SP $(n=22)$ & CON $(n=15)$ \\
\hline Heart Rate (bpm) & & \\
RE (1) & $106 \pm 14^{*}$ & $103 \pm 16$ \\
RE (2) & $125 \pm 14$ & $120 \pm 16$
\end{tabular}

SVIndex $\left(\mathrm{mL} \cdot \mathrm{m}^{-2}\right)$

$\operatorname{RE}(1)$

$59 \pm 12 *$

$50 \pm 5$

$\operatorname{RE}(2)$

$60+11$

$54+7$

QIndex $\left(L \cdot \mathrm{min}^{-1} \cdot \mathrm{m}^{-2}\right)$

$6.13 \pm 0.77^{*} \quad 5.15 \pm 1.12$

$\operatorname{RE}(1)$

RE (2)

$7.20+0.92 *$

$6.49+1.14$

$\mathrm{AVO}_{2}$ difference

$\left(\mathrm{mL} \cdot 100 \mathrm{~mL}^{-1}\right.$ )

$11.4 \pm 1.5$

$11.5 \pm 2.4$

RE (1)

RE (2)

$11.8+1.3$

$11.5+1.9$

SYSTOLIC FUNCTION

$\mathrm{S}^{\prime} \operatorname{adj}\left(\mathrm{cm} \cdot \mathrm{s}^{-1} \cdot \mathrm{mm}^{-1}\right)$

RE (1)

$1.8 \pm 0.3$

$1.7 \pm 0.3$

RE (2)

$2.0 \pm 0.4$

$2.0 \pm 0.3$

This article is protected by copyright. All rights reserved. 
$\operatorname{RE}(1)$

RE (2)

$E^{\prime} \operatorname{adj}\left(\mathrm{cm} \cdot \mathrm{s}^{-1} \cdot \mathrm{mm}^{-1}\right)$

$\mathrm{RE}(1)$

$0.25+0.04$

$0.23+0.04$

$\operatorname{RE}(2)$

$0.26 \pm 0.05$

$0.26 \pm 0.04$

$E / E^{\prime}$

$\mathrm{RE}(1)$

$6.9 \pm 1.1$

$6.7 \pm 0.9$

RE (2)

$7.5 \pm 1.4$

$6.9 \pm 0.9$

${ }^{*} \mathrm{P}<0.05$. Stroke volume adjusted for body surface area (SVIndex) and cardiac output adjusted for body surface area (QIndex). Arterial venous oxygen difference $\left(\mathrm{AVO}_{2}\right)$. Peak early diastolic filling velocity $(E)$. Peak longitudinal mitral annular velocities in systole $\left(S^{\prime}\right)$ and early diastole ( $\left.E^{\prime}\right)$. Both $E^{\prime}$ and $S^{\prime}$ were adjusted (adj) for heart size by LV length. E/E' was calculated as an estimate of LV filling pressure and thus preload. Relative Intensity $1(\mathrm{RE}(1))$ corresponds to $46.5 \% \mathrm{VO}_{2}$ peak in the control participants and $46.7 \%$ in the soccer players. Relative Intensity $2(\operatorname{RE}(2))$ corresponds to $60.5 \% \mathrm{VO}_{2}$ peak in the control participants and $56.8 \%$ in the soccer players.

This article is protected by copyright. All rights reserved. 
-O- Soccer Players

-7. Controls
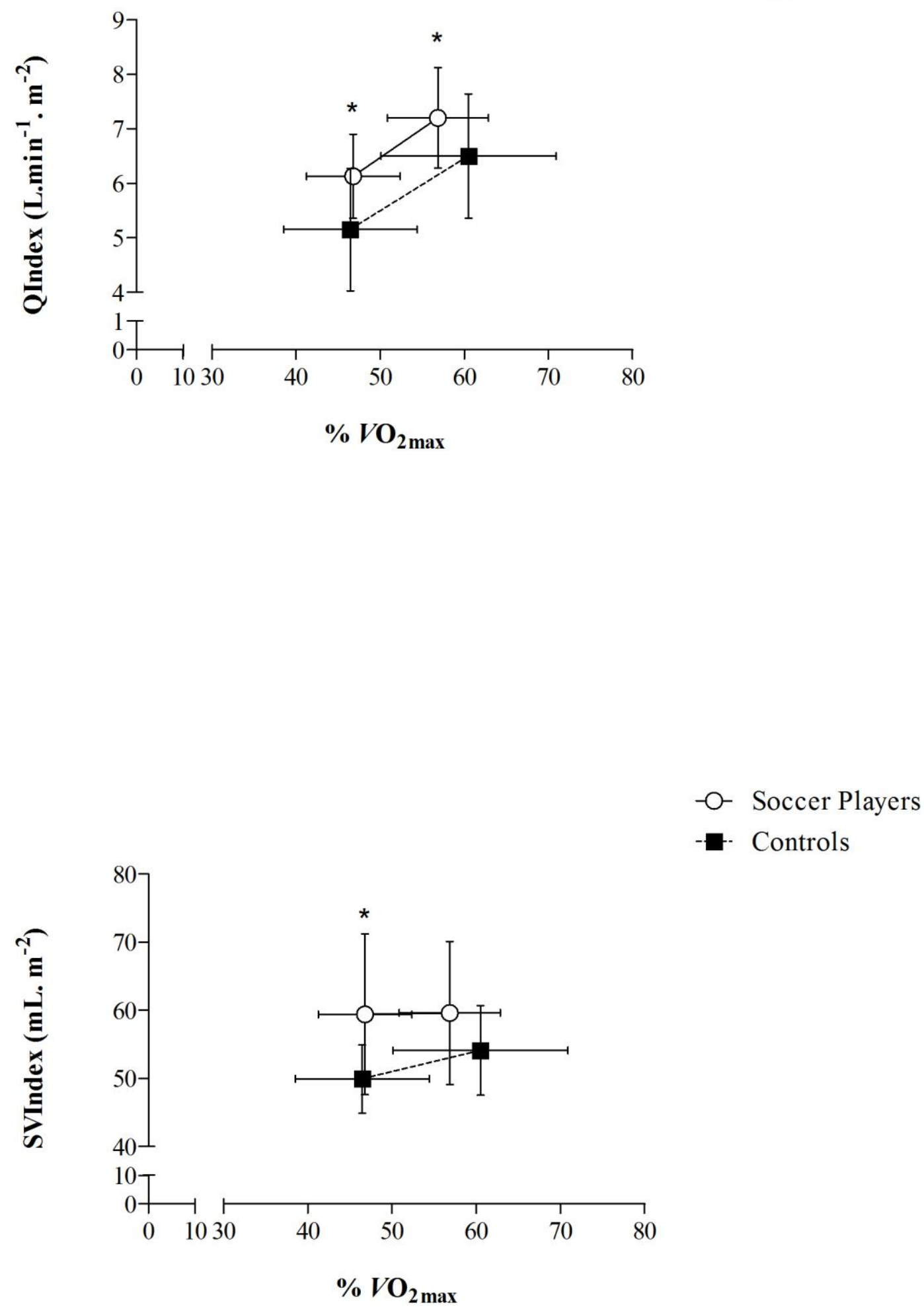

This article is protected by copyright. All rights reserved. 
-O- Soccer Players

-․ Controls

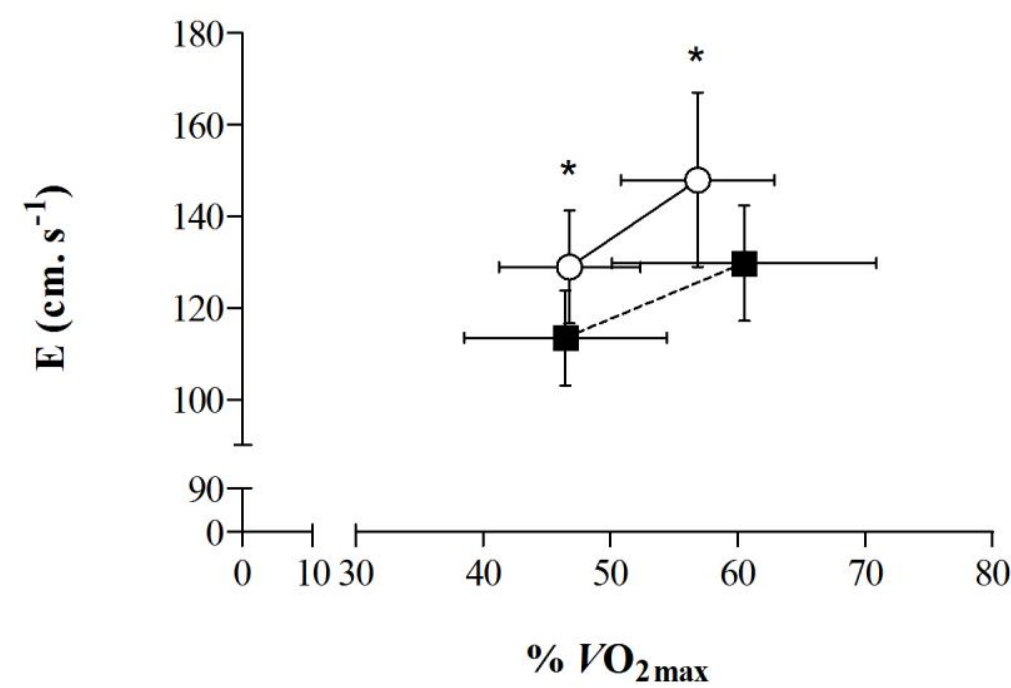

This article is protected by copyright. All rights reserved. 